\title{
2007/13
}

Income taxation of couples and the tax unit choice

Helmuth Cremer, Jean-Marie Lozachmeur and Pierre Piestieau 


\title{
CORE DISCUSSION PAPER
}

$2007 / 13$

\section{Income taxation of couples and the tax unit choice}

\author{
Helmuth CREMER ${ }^{1}$, Jean-Marie LOZACHMEUR ${ }^{2}$ \\ and Pierre PESTIEAU ${ }^{3}$
}

June 2006,

Revised February 2007

\begin{abstract}
This paper studies the optimal non linear income tax of couples. We build a general unitary model of labor supply and allow multidimensional heterogeneity in a discrete type framework. We concentrate our analysis on the resulting intra-family labor allocation of labor supplies and show that this analysis is strongly related to the choice of the tax unit (individual versus joint taxation). We give a necessary condition to have fully joint taxation in this framework and discuss some examples.
\end{abstract}

\footnotetext{
${ }^{1}$ GREMAQ and IDEI, University of Toulouse, France. E-mail: helmuth@ cict.fr

${ }^{2}$ GREMAQ, University of Toulouse, France.

${ }^{3}$ CREPP, Université de Liège and CORE, Université catholique de Louvain, Belgium; and PSE, France. E-mail: p.pestieau@ulg.ac.be

This paper presents research results of the Belgian Program on Interuniversity Poles of Attraction initiated by the Belgian State, Prime Minister's Office, Science Policy Programming. The scientific responsibility is assumed by the authors.
} 


\section{Introduction}

The tax treatment of couples has been a heavily debated subject among economists and noneconomists alike. Family taxation rules continue to differ significantly across countries, even though there appears to be a trend towards more "individualized" tax system. It does appear that family (or couple) based schemes tend to be replaced by systems that rely on the individual as the relevant tax unit. Accordingly, an individual's tax liability depends less than previously on the spouse's income. This trend has been observed over the last decades in most tax reforms in OECD countries. Nevertheless, in some countries like France, the systems remain to a substantial part family-based.

Accounting for the family dimension when studying optimal income taxation thus appears to be highly important. Among economists, it is generally admitted that the couple's secondary earner is also the one with the higher elasticity of labor supply (e.g. see Blundell and MaCurdy, 1999). Following the traditional Ramsey rule, the secondary wage earner should face a lower linear tax (see Boskin, 1975 and Boskin and Sheshinski, 1983). This pleads in general for a tax unit that is based on individual incomes. However, an individual's welfare largely depends upon the total couple's income. Thus it may be desirable to introduce a certain degree of progressivity depending upon the family's income.

The literature on this topic is quite scarce and restrictive. Following the seminal paper by Boskin (1975) and Boskin and Sheshinsky (1983), authors have usually constrained the analysis of optimal family income taxation to the framework of only linear instruments. ${ }^{1}$ As a result, the choice of the tax unit only depends upon the difference between optimal tax rates of the primary and the secondary earners: joint taxation is desirable if and only if these two tax rates are equal.

In reality, the picture is however more complicated than that. The taxation of a couple typically depends upon the primary and the secondary labor incomes. On one extreme, there is pure joint taxation if the tax function depends only on the sum of these two incomes. As a result, the marginal tax rate is the same for both spouses of

\footnotetext{
${ }^{1}$ Exemples are papers by Apps and Rees $(1988,1999)$ or more recently Kleven (2004).
} 
the same couple. On the other extreme we have individual taxation under which the tax paid by the family is the addition of two tax functions each depending only upon one spouse's income. In this situation, the tax unit is purely based on individual incomes, but this does not however preclude the case where both spouses' marginal tax rates are equal. Between these two polar cases, joint taxation and individual taxation, the most widespread system is one of selective taxation under which secondary earners, usually women, are taxed on a separate, lower, progressive tax schedule than that of primary earners.

The design of the tax function is often expressed in terms of the choice of the "tax unit": couple versus individual. Thus joint taxation corresponds to choosing the couple as the tax unit, with their combined income being the tax base while individual and selective taxation have the individual as the tax unit and the individual income as tax base. In this paper we study the conditions that lead to a specific tax system, particularly the joint one. Our approach is in the tradition of non-linear optimal income taxation. We thus assume away some of the considerations that can explain the observed move towards individualization of tax rules. One of them is ethical and reflects the view individuals should be given priority over couples in the name of responsibility. Another one is informational: marital status is assumed to be observable. This is a strong assumption because we live in a world with a wide variety of living arrangement and it is not always easy for tax authorities to sort out them. Typically couples can pretend living separately if they find it more attractive in terms of tax burden.

We study the optimal income taxation of couples in a nonlinear framework (Mirrlees, 1971). To the best of our knowledge, only two papers have studied this issue. The first one is the paper by Shroyen (2003) who studies optimal nonlinear income taxation in a setting where labor supply decisions are made within the household (couple) while the tax schedule is by assumption based on individual filing. He shows that the household structure and particularly the mating pattern affects the structure of an individual based income tax. The second paper is the one by Kleven et al. (2005). They study a general problem of optimum taxation of two wage earners family allowing multidimensional differences across families within a unitary model (of family decision making). They are 
interested in determining whether the tax function is separable into two individuals and independent tax schedules and in the asymptotic design of these tax functions.

Our contribution is very much complementary to the one of Kleven et al. (2005). We use a general setting where families are composed of two wage earners each characterized by a possibly different productivity (thus allowing for multidimensional heterogeneity). Our paper also uses the basic unitary model of the family but we assume a discrete distribution of productivities. We study the intra family allocation of labor supplies that is implied by the tax system. In other words, we examine wether the optimal (second-best) allocation distorts one spouse's labor supply relative to that of the other's spouse for a given level of gross income earned by the family. This issue, in turn, is strongly connected to the choice of tax unit. We show that pure joint taxation (with total household income as tax base) is equivalent to having no distortion in the allocation of both spouses' labor supplies for a given level of family income. We derive a general property stating if and how the intra-family allocation of labor is distorted. We also show in more restrictive settings how this condition can be related to the primitives of the model. To sum up, unlike Kleven et al. we are not interested in the separability of the household tax function but we examine whether a non separable function should depend solely on the sum of income or depend on the individual spouses income in a more complicated way.

\section{The model}

\subsection{Couples: preferences and productivities}

Consider a couple composed of two individuals indexed by $j=w, h$. The couple's preferences over its net income $x$ and labor supplies $l_{j}(j=w, h)$ are represented by a quasi-concave family utility function $U\left(x, l_{w}, l_{h}\right)$, with $\partial U / \partial x>0$ and $\partial U / \partial l_{j}<0$. The society is composed of $N$ types of couples indexed by superscript $i(i=1, \ldots, N)$ who differ in their members' labor productivities $a_{w}^{i}$ and $a_{h}^{i}$. The proportion of type $i$ couples in the economy is denoted by $\pi_{i}$ where $\sum_{i=1}^{N} \pi_{i}=1$. The total number of 
couples is normalized at one for notational convenience. ${ }^{2}$

\subsection{Tax instruments and labor supply decisions}

As in traditional models of optimal taxation, we assume that the individual productivities and labor supplies are not publicly observable. For any couple, however, before tax incomes of each of the spouses, $y_{w}^{i}=a_{w}^{i} l_{w}^{i}$ and $y_{h}^{i}=a_{h}^{i} l_{h}^{i}$ are observable. The tax policy consists of a non linear $\operatorname{tax} T\left(y_{w}^{i}, y_{h}^{i}\right)$ on the labor incomes of the two wage earners. This general tax function may exhibit some specific properties. In reality, tax functions range from "unitary taxation" to "separable taxation". ${ }^{3}$ In the first case, the tax function only depends upon the total income of the couple i.e. $T\left(y_{w}^{i}, y_{h}^{i}\right)=\widetilde{T}\left(y_{w}^{i}+y_{h}^{i}\right)$. In the second case, the tax levied on the income of one spouse does not depend upon the income earned by the other spouse i.e. $T\left(y_{w}^{i}, y_{h}^{i}\right)=\widehat{T}\left(y_{w}^{i}\right)+\widehat{T}\left(y_{h}^{i}\right)$. As mentioned in the introduction, much of the existing literature, has concentrated on the class of linear tax functions. The main question addressed in these papers is whether or not the income of both spouses should be taxed at the same (marginal) tax rate. We reconsider this question with nonlinear tax instruments. In such a setting the issue of equal or unequal marginal tax rate within the couple is particularly interesting because it is closely related to the issue of the choice of the tax base. The requirement that marginal tax rates are equal, namely

$$
\partial T\left(y_{w}^{i}, y_{h}^{i}\right) / \partial y_{w}^{i}=\partial T\left(y_{w}^{i}, y_{h}^{i}\right) / \partial y_{h}^{i}, \quad \forall i=1, \ldots, N
$$

is a necessary condition to have a unitary taxation system. It is also sufficient in the sense that when this condition holds for all couples the optimal allocation can be

\footnotetext{
${ }^{2}$ This model of the couple is a fairly general reduced form of the unitary model. It is consistent with the existence of "private" and "public" goods in the household and with the determination of consumption and labor supply levels though a bargaining process (where the weights are exogenous and not affected by the tax policy). From that perspective, one can think of $U\left(x, l_{w}, l_{y}\right)$ as the value function associated with the problem of allocating a household budget $x$ to the various consumption goods, given labor supply levels $l_{w}$ and $l_{y}$. In other words, $U\left(x, l_{w}, l_{y}\right)$ specifies the maximum level of the households objective (e.g., a weighted sum of utilities or a Nash product) given labor supplies and given its total (after tax budget). Using this reduced form rather than the original household objective in the optimal tax problem does not involve any loss of generality as long as differential commodity taxation is not possible, for instance because individual consumption levels (and thus the allocation of goods within the couple) are not publicly observable.

${ }^{3}$ This is admittedly a highly stylized and incomplete typology. In particular it abstracts from the tax treatment of children and relies on the assumption that there are no single individuals.
} 
implemented by a unitary tax function. ${ }^{4}$

Condition (1) is particularly interesting because it implies that the tax system does not distort the intra-family allocation of labor supply. To be more precise, for a given level of after tax income the labor allocation between the two spouses is not affected by such a tax function. To see this, note that for a given level of after tax income $x=y_{w}+y_{h}-T\left(y_{w}, y_{h}\right)$, the couple chooses $\left(y_{w}, y_{h}\right)$ to solve:

$$
\begin{aligned}
& \max _{y_{h}, y_{f}} U\left(x, \frac{y_{w}}{a_{w}}, \frac{y_{h}}{a_{h}}\right) \\
& \text { s.t. } x=y_{h}+y_{w}-T\left(y_{w}, y_{h}\right)
\end{aligned}
$$

Deriving the FOC and rearranging yields

$$
M R S_{y_{w}, y_{h}}=\frac{\partial U / \partial y_{h}}{\partial U / \partial y_{w}}=\frac{a_{w}}{a_{h}} \frac{\partial U / \partial l_{h}}{\partial U / \partial l_{w}}=\frac{1-\partial T\left(y_{h}, y_{w}\right) / \partial y_{h}}{1-\partial T\left(y_{h}, y_{w}\right) / \partial y_{w}}
$$

The tradeoff between $y_{w}$ and $y_{h}$ is not distorted (with respect to a first-best and/or laissez-faire outcome) when $M R S_{y_{w}, y_{h}}=1$. This is of course always the case when there are no taxes at all. More interestingly, equation (4) shows that the tradeoff remains undistorted as long as $\partial T\left(y_{h}, y_{w}\right) / \partial y_{h}=\partial T\left(y_{h}, y_{w}\right) / \partial y_{w}$, i.e., when the marginal tax on labor income is the same for both spouses. ${ }^{5}$ Based on the same arguments, we will say that the choice between $y_{w}$ and $y_{h}$ is distorted towards more $y_{h}$ (resp. $y_{w}$ ) when $\partial T\left(y_{h}, y_{w}\right) / \partial y_{w}>\partial T\left(y_{h}, y_{w}\right) / \partial y_{h}\left(\operatorname{resp} . \partial T\left(y_{h}, y_{w}\right) / \partial y_{w}<\partial T\left(y_{h}, y_{w}\right) / \partial y_{h}\right)$.

An alternative view on these distortions consists in saying that the choice between $y_{w}$ and $y_{h}$ is distorted towards less $y_{w}$ if couples who choose to decrease $y_{w}$ pay less taxes for a given level of total before tax income $G I=y_{w}+y_{h}$ that is when: ${ }^{6}$

$$
\left.\frac{d T\left(y_{h}, y_{w}\right)}{d y_{w}}\right|_{y_{w}+y_{h}=G I}=\frac{\partial T\left(y_{h}, y_{w}\right)}{\partial y_{w}}-\frac{\partial T\left(y_{h}, y_{w}\right)}{\partial y_{h}}>0
$$

\footnotetext{
${ }^{4}$ Which does not necessarily imply that all implementing tax functions are unitary.

${ }^{5}$ When marginal taxes are different from zero, leisure-labor and/or domestic labor-market labor tradeoffs are distorted. However, the intra-familly allocation of labor supply (as specified by problem (2)) remains undistorted when marginal tax rates are the same for both spouses.

${ }^{6}$ Similarly, there will be a distortion towards less $y_{h}$ in the $\left(y_{w}, y_{h}\right)$ tradeoff when:
}

$$
\left.\frac{d T\left(y_{h}, y_{w}\right)}{d y_{w}}\right|_{G I}=\frac{\partial T\left(y_{h}, y_{w}\right)}{\partial y_{w}}-\frac{\partial T\left(y_{h}, y_{w}\right)}{\partial y_{h}}<0 .
$$




\section{The optimal tax function}

We characterize the (constrained) Pareto efficient allocations that are obtained by maximizing a weighted sum of utilities subject to the resource constraint and the incentive compatibility constraints. The weight of a type $i$ couple is denoted $\alpha^{i} \pi^{i}$ with $\alpha^{i} \geq 0$ and $\sum_{i} \alpha^{i}=1$. For the remainder of the paper, we denote the utility function of a type $i$ couple by $U^{i}\left(x^{i}, y_{w}^{i}, y_{h}^{i}\right)=U\left(x^{i}, y_{w}^{i} / a_{w}^{i}, y_{h}^{i} / a_{h}^{i}\right)$. Because types are private information the following incentive compatibility constraints apply for any $i, j=1, \ldots, N$,

$$
U^{i}=U^{i}\left(x^{i}, y_{w}^{i}, y_{h}^{i}\right) \geq U^{i j}=U^{i}\left(x^{j}, y_{w}^{j}, y_{h}^{j}\right)
$$

In words, couple $i$ must not be able to achieve a (strictly) larger utility level by mimicking couple $j$, i.e., by consuming the consumption bundle designed for couple $j$.

Formally, a Pareto efficient allocation is the solution to the following problem:

$$
\begin{aligned}
\max _{x_{z}^{i}, y_{w}^{i}, y_{f}^{i}} & \sum_{i=1}^{N} \alpha^{i} \pi^{i} U^{i} \\
\text { s.t } & \sum_{i=1}^{N} \pi^{i}\left(y_{w}^{i}+y_{h}^{i}-x^{i}\right) \geq G \\
& U^{i} \geq U^{i j} i, j=1 \ldots \ldots . N
\end{aligned}
$$

where $G$ is the exogenous revenue requirement while $U^{i}$ and $U^{i j}$ are defined by (5).

Denoting the multipliers of constraints (6) and (7) by $\mu$ and $\lambda^{i j}$ respectively, one can write the Lagrangian expression as follows:

$$
\Lambda=\sum_{i=1}^{N} \alpha^{i} \pi^{i} U^{i}+\mu\left[\sum_{i=1}^{N} \pi^{i}\left(y_{w}^{i}+y_{h}^{i}-x^{i}\right)-G\right]+\sum_{i, j=1}^{N} \lambda^{i j}\left[U^{i}-U^{i j}\right]
$$

The first order conditions with respect to $y_{w}^{i}$ and $y_{h}^{i}, i=1 \ldots N$, are given by:

$$
\begin{aligned}
& \frac{\partial \Lambda}{\partial y_{w}^{i}}=\left[\alpha^{i} \pi^{i}+\sum_{i=1}^{N} \lambda^{i j}\right] \frac{\partial U^{i}}{\partial y_{w}^{i}}+\pi^{i} \mu-\sum_{j=1}^{N} \lambda^{j i} \frac{\partial U^{j i}}{\partial y_{w}^{i}}=0 \\
& \frac{\partial \Lambda}{\partial y_{h}^{i}}=\left[\alpha^{i} \pi^{i}+\sum_{i=1}^{N} \lambda^{i j}\right] \frac{\partial U^{i}}{\partial y_{h}^{i}}+\pi^{i} \mu-\sum_{j=1}^{N} \lambda^{j i} \frac{\partial U^{j i}}{\partial y_{h}^{i}}=0
\end{aligned}
$$


Denoting $\gamma^{i}=\alpha^{i} \pi^{i}+\sum_{i=1}^{N} \lambda^{i j}$ and combining equations (8) and (9) yields:

$$
\gamma^{i} \frac{\partial U^{i}}{\partial y_{w}^{i}} M R S_{y_{w}, y_{h}}^{i}+\gamma^{i} \frac{\partial U^{i}}{\partial y_{w}^{i}}-\sum_{j=1}^{N} \lambda^{j i} \frac{\partial U^{j i}}{\partial y_{w}^{i}} M R S_{y_{w}, y_{h}}^{j i}-\sum_{j=1}^{N} \lambda^{j i} \frac{\partial U^{j i}}{\partial y_{w}^{i}}=0
$$

where $M R S_{y_{w}, y_{h}}^{j i}=\partial U^{j i} / \partial y_{h}^{i} / \partial U^{j i} / \partial y_{w}^{i}$. After some rearrangements this yields:

$$
M R S_{y_{w}, y_{h}}^{i}=\frac{\gamma^{i} \frac{\partial U^{i}}{\partial y_{w}^{i}}-\sum_{j=1}^{N} \lambda^{j i} \frac{\partial U^{j i}}{\partial y_{w}^{i}}}{\gamma^{i} \frac{\partial U^{i}}{\partial y_{w}^{i}}-\sum_{j=1}^{N} \lambda^{j i} \frac{\partial U^{j i}}{\partial Y_{w}^{i}} \frac{M R S_{y w}^{j i}, y_{h}}{M R S_{y_{w}, y_{h}}^{i}}}
$$

Combining (10) with (4) and rearranging then establishes the following proposition; see Appendix A.

Proposition 1 (i) We have $\partial T\left(y_{w}^{i}, y_{h}^{i}\right) / \partial y_{w}^{i} \gtreqless \partial T\left(y_{w}^{i}, y_{h}^{i}\right) / \partial y_{h}^{i}$ if and only if

$$
\sum_{j=1}^{N} \lambda^{j i} \frac{\partial U^{j i}}{\partial y_{w}^{i}}\left[\frac{M R S_{y_{w}, y_{h}}^{j i}}{M R S_{y_{w}, y_{h}}^{i}}-1\right] \lesseqgtr 0
$$

(ii) A Pareto efficient allocation can be implemented by a unitary tax function $T\left(y_{w}^{i}, y_{h}^{i}\right)=$ $\widetilde{T}\left(y_{w}^{i}+y_{h}^{i}\right)$ if and only if condition (11) holds as equality for all couples $i=1, \ldots N$.

Proposition 1 provides a general condition under which a couple's tradeoff between the spouses' labor supplies should not be distorted; specifically this is true when the LHS of (11) is equal to zero. Otherwise, it ought to be distorted and the direction of the distortion is provided by (11). When the LHS of this condition is negative, $w$ faces a higher marginal tax rate than $h$ and the tradeoff is distorted towards more $y_{h}$. If it is negative, we have the opposite result. This condition is general in the sense that it is valid whatever the pattern of binding incentive constraints and for any welfare weights. The price to pay for this level of generality is that the condition involves endogenous variables. We shall show below that (11) reduces to a condition on the primitives of the model in special cases. In those cases the interpretation will also be facilitated. In the meantime let us have a look at the interpretation of the general condition.

To do this, let us first compare the choices of labor supplies, $\left(y_{w}, y_{h}\right)$, by couples $i$ and $j$ for a given level of gross income $G I=y_{w}+y_{h}$. Each couple chooses a pair $\left(y_{w}, y_{h}\right)$ that lies at the point of tangency between indifference curves and the gross income line 
i.e., where $M R S_{y_{w}, y_{h}}^{j}=M R S_{y_{w}, y_{h}}^{i}=1$. Figure 1 illustrates this choice in the $\left(y_{h}, y_{w}\right)$ plane where couples $j$ and $i$ choose a different combination of spouses' gross incomes. In the case that is depicted, the marginal rate of substitution between $y_{w}$ and $y_{h}$ is larger (in absolute value) for couple $j$ than for couple $i$, so that it chooses a higher $y_{w}$ and a lower $y_{h}$. Now assume that the incentive compatibility constraint preventing couple $j$ to mimic couple $i$ is binding and note that at the point $\left(y_{w}^{i}, y_{h}^{i}\right)$ couple $j$ has a steeper indifference curve than couple $i$. To make couple $i$ 's consumption bundle $\left(y_{w}^{i}, y_{h}^{i}\right)$ less attractive for couple $j$, it is then desirable to distort the choice of couple $i$ towards less $y_{w}$ (moving to the right along the income line). In other words, a higher marginal tax on $y_{w}^{i}$ would be desirable to relax an otherwise binding incentive compatibility constraint. Alternatively, when the marginal rate of substitution is lower (in absolute value) for couple $j$ then it is desirable to distort the choice of couple $i$ towards more $y_{w}$ i.e. to have a higher marginal tax on $y_{h}$.

So far we have concentrated on one pair of couples. However, the solution may well imply that several incentive constraints towards type $i$ are binding. Condition (11) considers all couples $j$ for which the incentive compatibility constraints towards the type $i$ couple is binding i.e. all the $j$ such that $\lambda^{j i}>0$. For each binding incentive compatibility constraint, there is a desirable distortion on the $\left(y_{w}^{i}, y_{h}^{i}\right)$ choice. As argued above, the sign of this distortion depends upon the difference between the two couples in the marginal rates of substitution. Proposition 1 states that the total distortion on couple $i$ 's $\left(y_{w}^{i}, y_{h}^{i}\right)$ tradeoff depends upon a weighted sum of distortions imposed by each binding self-selection constraints in which $i$ is the mimicked type.

Observe that a couple $i$ such that $\lambda^{j i}=0$ for all $j$ (if it exists) never faces a distortion (the LHS of (11)) is always equal to zero). This is the counterpart to the traditional no distortion at the top result in this multi-dimensional setting. For all other types $i$ (with at least one $\lambda^{j i}>0$ ) the LHS of (11) may or may not be zero, depending on the marginal rates of substitution of the mimicker and the mimicked couples. A sufficient condition for this to be the case is that $M R S_{y_{w}, y_{h}}^{j i}=M R S_{y_{w}, y_{h}}^{i}$ at the point $\left(y_{w}^{i}, y_{h}^{i}\right)$ for all pairs of couples with $\lambda^{j i}>0$. In words, this (sufficient) condition requires that all pairs of couples linked by a binding incentive constraint have the same marginal rate 


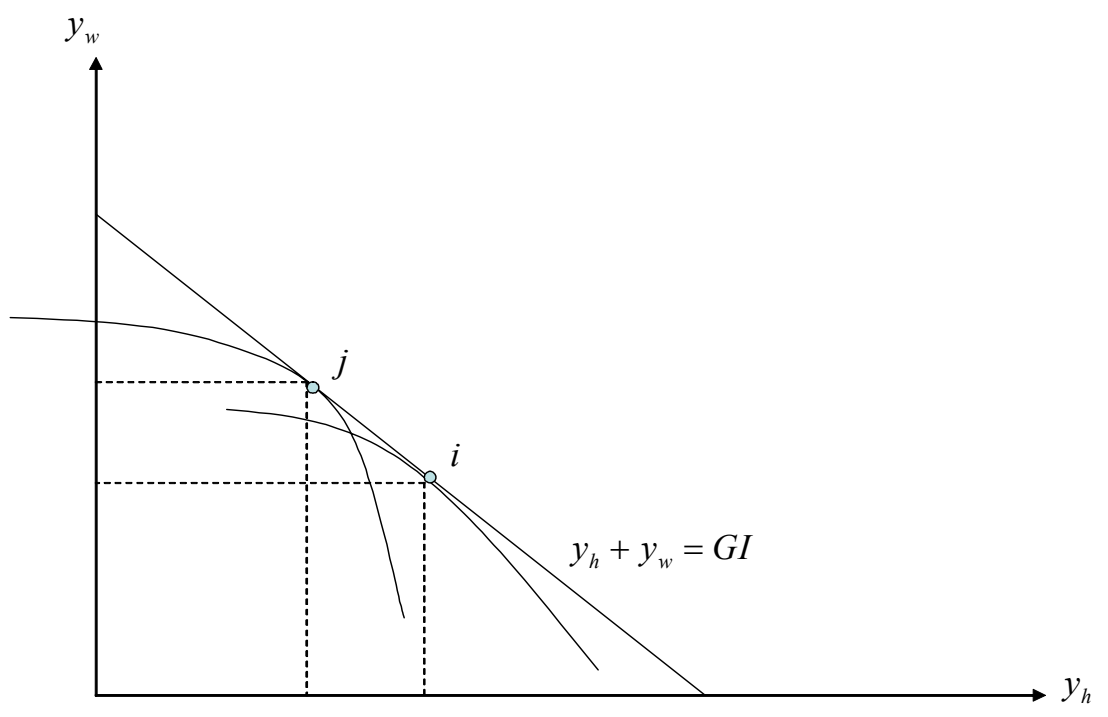

Figure 1: The $\left(y_{w}, y_{h}\right)$ choice for a given level of gross income $G I$. 
of substitution (at the labor supply bundle of the mimicked couple).

A more intuitive version of this condition, based solely on exogenous variables, can be obtained for specific classes of utility functions. The following proposition is established in Appendix B.

Proposition 2 Assume couples utility functions are of the form

$$
U(x, l)=u(x)-l_{w}^{\beta}-l_{h}^{\beta},
$$

where $\beta \geq 1$. Then, a sufficient condition to have $\partial T\left(y_{w}^{i}, y_{h}^{i}\right) / \partial y_{w}^{i}=\partial T\left(y_{w}^{i}, y_{h}^{i}\right) / \partial y_{h}^{i}$ is:

$$
\frac{a_{w}^{j}}{a_{h}^{j}}=\frac{a_{w}^{i}}{a_{h}^{i}} \text { for all } i, j=1 \ldots N .
$$

In words, condition (13) requires that the ratio of the two spouses' productivities be the same for all couples. The underlying mating pattern thus implies a perfect correlation between the two productivities of the two spouses. In a society with assortative mating as opposed to random (or reverse) mating condition (13) could be verified. Some studies suggest that most industrial societies are moving towards assortative mating: couples are becoming more and more similar over time; see e.g., Rose (2001).

The case of iso-elastic utilities is further explored in the following two-types example. It provides a nice illustration and more significantly, it yields more precise results regarding the sign of the distortions.

\section{A two types example}

Suppose there are only two types of couples in the economy. The couple 1 is characterized by higher productivities than couple 2, i.e., $a_{w}^{1} \geq a_{w}^{2}$ and $a_{h}^{1} \geq a_{h}^{2}$. Assume further that the incentive compatibility constraint preventing type 1 to mimic type 2 is binding i.e. $\lambda_{12}>0 .^{7}$ In this case, there is no distortion for type 1. Furthermore, Proposition

\footnotetext{
${ }^{7}$ This is equivalent to assume that $\alpha^{2}$ is high enough in the objective of the government.
} 
1 (i) is equivalent to

$$
\begin{aligned}
\partial T\left(y_{w}^{2}, y_{h}^{2}\right) / \partial y_{w}^{2} & \gtreqless \partial T\left(y_{w}^{2}, y_{h}^{2}\right) / \partial y_{h}^{2} \\
& \Leftrightarrow \\
M R S_{y_{w}, y_{h}}^{12} & \gtreqless M R S_{y_{w}, y_{h}}^{2} .
\end{aligned}
$$

With iso-elastic disutility of labor, so that $U(x, l)=u(x)-l_{w}^{\beta}-l_{h}^{\beta}(\beta \geq 1)$, one has:

$$
\frac{M R S_{y_{w}, y_{h}}^{2}}{M R S_{y_{w}, y_{h}}^{12}}=\left(\frac{a_{w}^{2} / a_{h}^{2}}{a_{w}^{1} / a_{h}^{1}}\right)^{\beta}
$$

Consequently, a necessary and sufficient condition to have a solution that can be implemented by a unitary tax function is that the ratio between the spouses productivities is the same for both types of couples. This is essentially just an illustration of Proposition 2. More interestingly, (14) implies that $a_{w}^{2} / a_{h}^{2}>a_{w}^{1} / a_{h}^{1}$ yields $\partial T\left(y_{w}^{2}, y_{h}^{2}\right) / \partial y_{w}^{2}<\partial T\left(y_{w}^{2}, y_{h}^{2}\right) / \partial y_{h}^{2}$. In words, in the low productivity couple spouse $w$ faces a lower marginal tax rate than spouse $h$, when the ratio between the productivities of $w$ and $h$ is larger in the mimicked couple than in the mimicking couple. Put differently, female labor supply would be encouraged (relative to the male labor supply) in the low productivity couple when the wife is relatively more productive in that household than in the high productivity couple. With the considered profile of the spouses productivity ratios such a distortion has a more significant impact on the utility of the mimicking couple than on that of the mimicked couple and, as explained in the previous section, the differential taxation of the spouses incomes relaxes a binding incentive constraint. Conversely, $a_{w}^{2} / a_{h}^{2}<a_{w}^{1} / a_{h}^{1}$ yields $\partial T\left(y_{w}^{2}, y_{h}^{2}\right) / \partial y_{w}^{2}>\partial T\left(y_{w}^{2}, y_{h}^{2}\right) / \partial y_{h}^{2}$ and we have exactly the opposite result (but the same intuition).

\section{Conclusion}

Understanding the implications of optimal taxation theory for the fiscal treatment of couples is a big challenge. This paper is an attempt to explore one aspect of the problem. Specifically, we provide a general framework to study the intra-family labor allocation under an optimal nonlinear income tax schedule. Whether this allocation is distorted 
or not depends upon the tax unit choice. The literature distinguishes between two "tax units": the couple vs the individual. It also considers three tax systems: joint taxation, individual taxation and selective taxation. The first corresponds to choosing the couple as the tax unit while the second and the third have the individual as the tax unit.

We focus on joint taxation and provide the conditions that lead to such a system. We consider first a general setting and then two more restricted frameworks. Not surprisingly, these conditions are rather restrictive. For instance, when the family utility function is separable and the labor disutility function is isoelastic, a necessary condition for a pure joint taxation is the equality of the ratio between the two earners' productivity across all couples. We also study how the spouses respective labor supply decisions are distorted when the condition does not hold. In particular, we show in a two-type example that the way this ratio varies has a direct impact on the now different marginal tax of the two spouses.

It is important to note that the restrictive character of the assumptions that imply joint taxation does not mean that the assumptions needed to obtain separate taxation are less restrictive.

While allowing a quite general framework, our analysis suffers from an important drawback namely that it is based on the so-called unitary approach. It is well known that this approach is usually not supported by the empirical evidence. In the future, we plan to study such problems within the framework of collective models initiated by Chiappori (1988).

\section{Appendix}

\section{A Proof of Proposition 1}

Combining (4) and (10) yields

$$
\frac{1-\partial T\left(y_{h}^{i}, y_{w}^{i}\right) / \partial y_{h}^{i}}{1-\partial T\left(y_{h}^{i}, y_{w}^{i}\right) / \partial y_{w}^{i}}=\frac{\gamma^{i} \frac{\partial U^{i}}{\partial y_{w}^{i}}-\sum_{j=1}^{N} \lambda^{j i} \frac{\partial U^{j i}}{\partial y_{w}^{i}}}{\gamma^{i} \frac{\partial U^{i}}{\partial y_{w}^{i}}-\sum_{j=1}^{N} \lambda^{j i} \frac{\partial U^{j i}}{\partial y_{w}^{i}} \frac{M R S_{y w, y_{h}}^{j i}}{M R S_{y_{w}, y_{h}}^{i}}},
$$


so that

$$
\begin{gathered}
\partial T\left(y_{w}^{i}, y_{h}^{i}\right) / \partial y_{w}^{i} \gtreqless \partial T\left(y_{w}^{i}, y_{h}^{i}\right) / \partial y_{h}^{i} \Leftrightarrow \\
\frac{\gamma^{i} \frac{\partial U^{i}}{\partial y_{w}^{i}}-\sum_{j=1}^{N} \lambda^{j i} \frac{\partial U^{j i}}{\partial y_{w}^{i}}}{\gamma^{i} \frac{\partial U^{i}}{\partial y_{w}^{i}}-\sum_{j=1}^{N} \lambda^{j i} \frac{\partial U^{j i}}{\partial y_{w}^{i}} \frac{M R S_{y_{w}, y_{h}}^{j i}}{M R S_{y_{w}, y_{h}}^{i}}} \gtreqless 1 .
\end{gathered}
$$

Numerator and denominator of (15) are negative. Consequently this property is equivalent to

$$
\begin{aligned}
& T\left(y_{w}^{i}, y_{h}^{i}\right) / \partial y_{w}^{i} \gtreqless \partial T\left(y_{w}^{i}, y_{h}^{i}\right) / \partial y_{h}^{i} \Leftrightarrow \\
& \gamma^{i} \frac{\partial U^{i}}{\partial y_{w}^{i}}-\sum_{j=1}^{N} \lambda^{j i} \frac{\partial U^{j i}}{\partial y_{w}^{i}} \lesseqgtr \gamma^{i} \frac{\partial U^{i}}{\partial y_{w}^{i}}-\sum_{j=1}^{N} \lambda^{j i} \frac{\partial U^{j i}}{\partial Y_{w}^{i}} \frac{M R S_{y_{w}, y_{h}}^{j i}}{M R S_{y_{w}, y_{h}}^{i}}
\end{aligned}
$$

Simplifying and rearranging the last inequality establishes to Proposition 1.

\section{B Proof of Proposition 2}

When preferences are represented by (12) one has:

$$
\begin{aligned}
M R S_{y_{w}, y_{h}}^{i} & =\frac{\partial U^{i} / \partial y_{h}^{i}}{\partial U^{i} / \partial y_{w}^{i}}=\left(\frac{a_{w}^{i}}{a_{h}^{i}}\right)^{\beta}\left(\frac{y_{h}^{i}}{y_{w}^{i}}\right)^{\beta-1}, \\
M R S_{y_{w}, y_{h}}^{j i} & =\frac{\partial U^{j i} / \partial y_{h}^{i}}{\partial U^{j i} / \partial y_{w}^{i}}=\left(\frac{a_{w}^{j}}{a_{h}^{j}}\right)^{\beta}\left(\frac{y_{h}^{i}}{y_{w}^{i}}\right)^{\beta-1},
\end{aligned}
$$

so that

$$
\frac{M R S_{y_{w}, y_{h}}^{j i}}{M R S_{y_{w}, y_{h}}^{i}}=\left(\frac{a_{w}^{j} / a_{h}^{j}}{a_{w}^{i} / a_{h}^{i}}\right)^{\beta} .
$$

Consequently, it follows from Proposition 1 , that $a_{w}^{j} / a_{h}^{j}=a_{w}^{i} / a_{h}^{i}$ for all $i, j=1 \ldots N$, implies $M R S_{y_{w}, y_{h}}^{j i} / M R S_{y_{w}, y_{h}}^{i}-1=0$ and $\partial T\left(y_{w}^{i}, y_{h}^{i}\right) / \partial y_{w}^{i}=\partial T\left(y_{w}^{i}, y_{h}^{i}\right) / \partial y_{h}^{i}$. 


\section{References}

[1] Apps, P. and R. Rees, 1988, Taxation and the household, Journal of Public Economics, 75, 355-369.

[2] Apps, P. and R. Rees, 1999, Individual vs. Joint Taxation in Models with Household Production, Journal of Political Economy, 107, 393-403.

[3] Blundell R. and T. MaCurdy, 1999, Labor Supply: A Review of Alternative Approaches, in O. Ashenfelter and D. Card (eds), Handbook of Labor Economics vol 3A, Elsevier Science B.V., Amsterdam.

[4] Boskin, M., 1975, Efficiency aspects of the differentiated tax treatment of market and household economic activity, Journal of Public Economics, 4, 1-25.

[5] Boskin M.J. and E. Sheshinski, 1983, Optimal Tax treatment of the Family: Married Couples, Journal of Public Economics, 20, 281-297.

[6] Brett, C., 2006, Optimal nonlinear taxes for families, International Tax and Public Finance,

[7] Chiappori P.-A., 1988, Rational Household Labor Supply, Econometrica, 56, 1,6389.

[8] Chiappori P.-A., B. Fortin and G. Lacroix, 2002, Household Labor Supply, Sharing Rule and the Marriage Market, Journal of Political Economy, 110, 1, 37-72.

[9] Kleven H.J., 2004, Optimum Taxation and the Allocation of Time, Journal of Public Economics 88, 545-557.

[10] Kleven H.J., C.T. Kreiner and E. Saez (2005), The Optimal Income Taxation of Couples, Manuscript.

[11] Mirrlees, J A., 1971, An Exploration in the Theory of Optimal Income Taxation, Review of Economic Studies, 38, 175-208. 
[12] Rose, E., 2001, Marriage and assortative mating: how have the pattern changed?, University of Washington, unpublished.

[13] Schroyen, F., (2003), Redistributive taxation and the household: the case of individual filings, Journal of Public Economics, 87, 2527-2547. 